http://jmscr.igmpublication.org/home/ ISSN (e)-2347-176x ISSN (p) 2455-0450 crossref DOI: https://dx.doi.org/10.18535/jmscr/v7i8.09

Journal Of Medical Science And Clinical Research

\title{
Red Blood Cell Distribution Width as a Marker of Early Onset Neonatal Sepsis: A Hospital Based Analytical Study
}

\author{
Authors \\ Dr Monu Singh ${ }^{1}$, Dr S.Sitaraman ${ }^{2}$, Dr Richa Choudhary ${ }^{3}$, Dr Ajeet Singh Choudhary ${ }^{4}$ \\ ${ }^{1}$ Junior Resident, Dept. of Paediatrics, S.M.S. medical college \\ ${ }^{2}$ Senior professor and Head Dept. of Paediatrics, S.M.S. medical college \\ ${ }^{3}$ Asst. Professor, Dept. of Paediatrics, S.M.S. medical college \\ ${ }^{4}$ Junior Resident, Dept of Internal Medicine, S.M.S Medical College \\ *Corresponding Author \\ Dr Ajeet Singh Choudhary \\ Junior Resident, Dept of Internal Medicine, S.M.S Medical College, Jaipur, India
}

\begin{abstract}
Background: Neonatal sepsis is still a significant cause of neonatal morbidity\& mortality and its early diagnosis still remains a challenge. Present study aimed to investigate Red cell Distribution Width (RDW) as a marker of early onset neonatal sepsis (EONS).

Material and Methods: A hospital based cross sectional analytical study was conducted at department of paediatrics, at a tertiary care centre of western India, including 55 early onset neonatal sepsis cases and 55 controls. Newborn delivered by spontaneous vaginal delivery with gestational age of 36 weeks or more presenting within 72 hours of delivery with signs \& symptoms suggestive of early onset neonatal sepsis were taken as cases and age and weight-matched healthy new-born were taken as control.

Observations: Mean RDW level was significantly higher $(p<0.001)$ in EONS $(21.31 \pm 3.08 \%)$ as compared to healthy controls $(16.23 \pm 1.16 \%)$. TLC was also significantly higher $(p<0.001)$ in EONS $(18.92 \pm$ $\left.8.01 \times 10^{3} / \mathrm{dl}\right)$ as compared to controls $\left(12.19 \pm 9.29 \times 10^{3} / \mathrm{dl}\right)$. The area under the ROC curve for RDW was 0.988 (0.973 - 1.000), which indicated that RDW was a good predictor of EONS ( $p<0.001)$. The Critical cut off point was found to be 18.55 using Youden's index with a sensitivity of $94.55 \%$ and specificity of $96.36 \%$ for diagnosis of EONS.

Conclusion: Red cell distribution width can be used as a cheap, easy, rapid and accurate marker for rapid identification of early onset neonatal sepsis.

Keywords: Neonatal sepsis, early onset neonatal sepsis, Red cell distribution width, RDW.
\end{abstract}

\section{Introduction}

Neonatal Sepsis is an invasive infection occurring within the first 28 days of life. Despite advances in perinatal \& neonatal care, neonatal sepsis is still a significant cause of mortality \& morbidity. According to National Neonatal Perinatal Database (NNPD, 2002-03) incidence of neonatal sepsis in India was 30 per 1000 live births and it contributed to $18.6 \%$ of neonatal deaths, next to only perinatal asphyxia (28.8\%) and prematurity $(26.3 \%)^{[1]}$. Neonatal sepsis is defined as systemic inflammatory response syndrome in the presence of or as a result of suspected or proven infection ${ }^{[2]}$. It encompasses various systemic infections of 
the newborn such as Septicemia, Meningitis, Pneumonia, Arthritis, Osteomyelitis, and Urinary tract infections.

Early onset neonatal sepsis (EONS) presents within the first 72 hours of life. Infants with EONS usually present with respiratory distress and pneumonia. The source of infection is generally the maternal genital tract ${ }^{[3]}$. EONS constituted $67 \%$ of all neonatal sepsis cases in India $^{[1]}$. The micro-organisms most commonly associated include Group B Streptococcus, E. coli, Haemophilus influenzae and Listeria monocytogenes $^{[4]}$.

Risk factors associated with an increased risk of EONS include Low birth weight or prematurity, febrile illness in the mother with evidence of bacterial infection within 2 weeks prior to delivery, foul smelling liquor, rupture of membranes $>24$ hours, single unclean or $>3$ sterile vaginal examination(s) during labour, prolonged labour and perinatal asphyxia (Apgar score $<4$ at 1 minute).Immature immune defences in newborns, including low circulating levels of immunoglobulins, decreased number of $T$ lymphocytes and neutrophils, and functionally impaired cytotoxic activity in leukocytes ${ }^{[5-7]}$ are involved in pathogenesis of neonatal sepsis.

Diagnosis of early onset neonatal sepsis remains a challenge for neonatal health care providers. The gold standard for detecting bacterial sepsis is blood culture, but its positivity ranges from as low as $8 \%$ to $73 \%^{[8-10]}$ in the diagnosis of potential neonatal sepsis and it has limitation of 24 to 48 hour assay time. Low sensitivity of culture for identifying neonatal sepsis ${ }^{[5,11]}$ and limited accuracy and reliability of haematological markers have led to development of scoring system for diagnosis of EONS. These scoring systems include clinical and laboratory findings (total WBC counts, absolute number of neutrophils, immature/total neutrophil ratio) and acute phase reactants (CRP and procalcitonin) in different combinations $^{[5-9]}$.

Red blood cell distribution width (RDW) is a parameter reflecting the heterogeneity of the peripheral red blood volume and is usually expressed with RDW-coefficient of variation (RDW-CV). Limited information is available about the association between RDW and EONS ${ }^{[12]}$. This study, aimed to compare RDW levels in healthy new-born and those with EONS in order to investigate the potential role of $\mathrm{RDW}$ as a marker of EONS.

\section{Material and Methods}

This study was a hospital based cross sectional analytical study conducted at department of paediatric medicine, at a tertiary care centre of western India,. A total of 55 early onset neonatal sepsis cases and 55 controls presenting to the hospital over the period of sep-2017 to nov2018were taken into the study. Newborn delivered by spontaneous vaginal delivery with gestational age of 36 weeks or more presenting to the hospital within 72 hours of delivery with signs \& symptoms suggestive of early onset clinical infection or pneumonia with presence of foul smelling liquor or least two of the following risk factors - Febrile illness in the mother with evidence of bacterial infection within 2 weeks prior to delivery, rupture of membranes >24 hours, single unclean or $>3$ sterile vaginal examination (s) during labour.

Prolonged labour (sum of 1st and 2nd stage of labour $>24 \mathrm{hrs}$ ), Perinatal asphyxia (apgar score $<4$ at 1 minute). Age and body weight-matched healthy new-born in post natal ward or those brought to the outpatient clinics for neonatal screening program within 72 hours of delivery were taken as control. Very-low-birth $(<2500 \mathrm{~g})$ infants, those with perinatal asphyxia, meconium aspiration syndrome, congenital malformations, congenital infections associated with the TORCH complex, metabolic disease, $\mathrm{Rh}$ or $\mathrm{ABO}$ isoimmunisation or those delivered by Cesarean section were excluded from the study.

Eligible selected subjects were subjected to a detailed history, clinical examination \& laboratory evaluation. Peripheral blood samples were drawn 
during their first hospital visits and $\mathrm{CBC}$, and blood typing was determined.

Diagnosis of EONS was made according to following criteria:

1) Clinical signs consistent with infection based on the Töllner score or

2) Culture-positivity detected in blood, urine and cerebrospinal fluid samples or

3) Signs of pneumonia on chest X-ray.

Clinical parameters used in the Töllner scoring system include discoloration of skin, isordered Peripheral Circulation, Hypotonia, Bradycardia, Apnea and Respiratory Distress, Hepatomegaly, Abdominal Distension, Abnormal Laboratory Parameters (Left-Shift In WBC Counts, Thrombocytopenia) and Metabolic Acidosis. For each parameter one point is assigned. Patients were categorized clinical sepsis $(\geq 10$ pts $)$, suspicion of sepsis (5-10 pts) and normal ( $\leq 5 \mathrm{pts})$ new-born were categorized ${ }^{[7]}$.

Statistical Analysis: Nominal / categorical variables were summarized as frequency and percentage and analyzed using Chi square test. Continuous variables were summarized as mean and standard deviation and were analyzed using independent sample $\mathrm{t}$ test. Multivariate logistic regression analysis was done to determine the independent predictors of EONS. ROC curve was used to determine the role of RDW for diagnosis of EONS and to determine the critical cutoff using Youden index. A p value $<0.05$ was taken as statistically significant. All statistical analysis was done using SPSS trial version 20 statistical software.

\section{Observation}

The baseline characteristics of neonatal sepsis cases and healthy controls were comparable (Table 1). Mean RDW level was found to be significantly higher $(\mathrm{p}<0.001)$ in EONS cases $(21.31 \pm 3.08 \%)$ as compared to healthy controls $(16.23 \pm 1.16 \%)$. TLC was also found to be significantly higher $(\mathrm{p}<0.001)$ in EONS $(18.92 \pm$ $\left.8.01 \times 10^{3} / \mathrm{dl}\right)$ as compared to healthy controls $\left(12.19 \pm 9.29 \times 10^{3} / \mathrm{dl}\right)$. (Table 2). Multivariate logistic regression analysis showed that RDW $(\mathrm{OR}=50.39)$ and $\mathrm{TLC}(\mathrm{OR}=1.204)$ were independent predictors of EONS (Table 3). The area under the ROC curve for RDW was 0.988 $(0.973-1.000)$, which indicated that RDW was a good predictor of EONS $(\mathrm{p}<0.001)$. The Critical cut off point was found to be 18.55 using Youden's index which indicates that RDW $\geq 18.55$ was diagnostic of EONS (Figure 1). At cutoff of 18.5, RDW had $94.55 \%$ sensitivity and $96.36 \%$ specificity for diagnosis of EONS (Table 4).

Table 1: Baseline characteristics of study groups

\begin{tabular}{|l|c|c|c|}
\hline & Case $(\mathbf{N}=55)$ & Control (N=55) & \\
\hline Age in years; (mean \pm SD) & $26.56 \pm 19.0$ & $26.07 \pm 12.31$ & 0.873 \\
\hline Gender - Male & $37(\%)$ & $34(\%)$ & 0.690 \\
Female & $18(\%)$ & $21(\%)$ & \\
\hline Religion - Hindu & $47(\%)$ & $49(\%)$ & 0.775 \\
Muslim & $8(\%)$ & $6(\%)$ & 0.120 \\
\hline Gestational age in weeks & $38.20 \pm 1.16$ & $37.89 \pm 0.90$ & 0.267 \\
\hline Birth weight in Kg & $2.74 \pm 0.18$ & $2.67 \pm 0.39$ & 0.089 \\
\hline Hemoglobin in gm\% & $16.26 \pm 2.39$ & $15.56 \pm 1.87$ & 0. \\
\hline
\end{tabular}

Table 2: Comparison of Blood parameters among study groups

\begin{tabular}{|l|c|c|c|c|c|}
\hline \multirow{2}{*}{} & \multicolumn{2}{|c|}{ Case } & \multicolumn{2}{c|}{ Control } & \multirow{2}{*}{ P value } \\
\cline { 2 - 5 } & Mean & SD & Mean & SD & \\
\hline TLC $\left(\times 10^{3} / \mathrm{dl}\right)$ & 18.92 & 8.01 & 12.19 & 9.29 & $<0.001(\mathrm{~S})$ \\
\hline Platelet count $\left(\mathrm{x} 10^{5} / \mathrm{dl}\right)$ & 2.56 & 1.16 & 2.99 & 1.24 & 0.062 \\
\hline RDW $(\%)$ & 21.31 & 3.08 & 16.23 & 1.16 & $\mathrm{P}<0.001(\mathrm{~S})$ \\
\hline
\end{tabular}

TLC- Total leucocyte count; RDW- Red cell distribution width 
Table 3: Multivariate logistic regression analysis to determine predictors of EONS

\begin{tabular}{|l|c|c|c|c|c|c|}
\hline Variables & Odds ratio & \multicolumn{2}{|c|}{ 95\% C.I. } & Coefficient (B) & SE & P value \\
\hline Age & 0.942 & .858 & 1.034 & -0.060 & 0.048 & 0.209 \\
\hline Sex(Male) & .069 & .001 & 3.237 & -2.677 & 1.965 & 0.173 \\
\hline Religion(Muslim) & .007 & .000 & 3.254 & -4.973 & 3.139 & 0.113 \\
\hline Gestational Age & 1.793 & .253 & 12.689 & .584 & .998 & 0.559 \\
\hline Birth Weight & 8.14 & .006 & 46.6 & 4.473 & 4.407 & 0.311 \\
\hline Hemoglobin & 2.812 & 0.928 & 7.689 & 0.934 & .513 & 0.144 \\
\hline TLC & 1.204 & 1.016 & 1.427 & .185 & .087 & $0.033^{*}$ \\
\hline Platelet count & .382 & .091 & 1.598 & -.963 & .730 & 0.187 \\
\hline RDW & 50.39 & 3.239 & 784.113 & 3.920 & 1.400 & $0.005^{*}$ \\
\hline
\end{tabular}

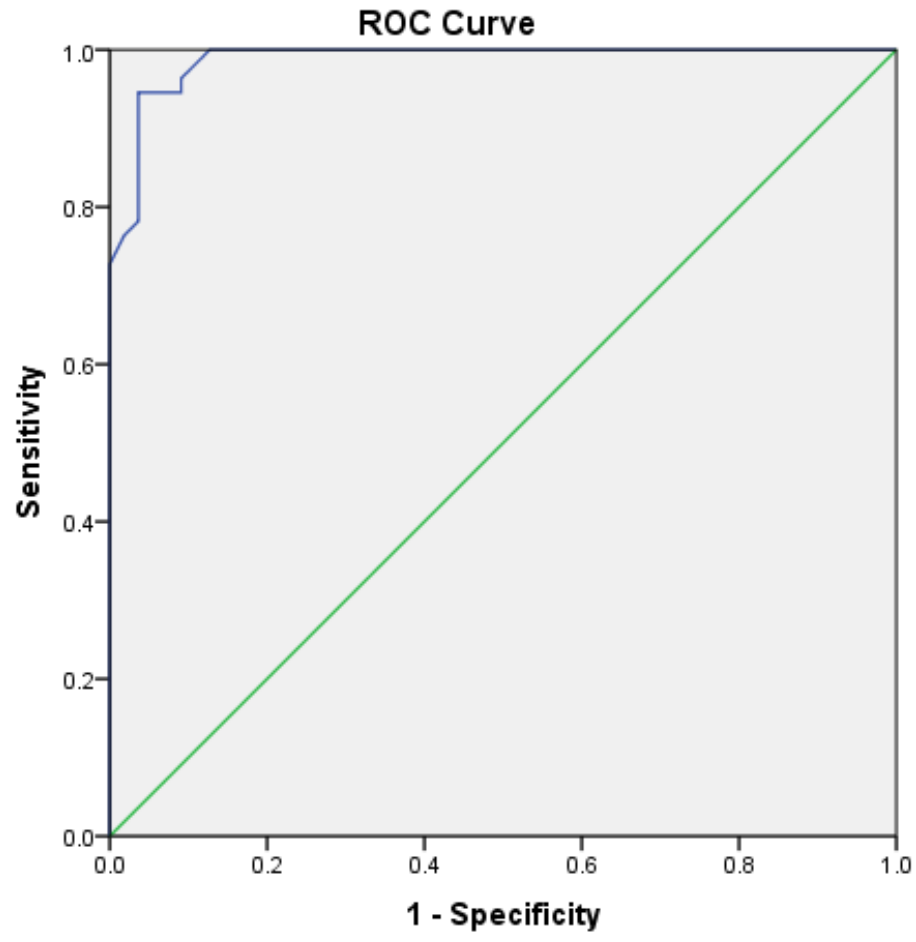

Diagonal segments are produced by ties.

Figure 1: ROC curve of RDW for diagnosis of EONS

Table 4: Diagnostic parameters of RDW for diagnosis of EONS

\begin{tabular}{|l|c|c|}
\hline Parameter & Value & 95\% CI \\
\hline Sensitivity & $94.55 \%$ & $85.15-98.13 \%$ \\
\hline Specificity & $96.36 \%$ & $87.46-98.98 \%$ \\
\hline PPV & $96.3 \%$ & $87.46-98.98 \%$ \\
\hline NPV & $94.64 \%$ & $85.39-98.16 \%$ \\
\hline Diagnostic accuracy & $95.45 \%$ & $89.8-98.04 \%$ \\
\hline
\end{tabular}

\section{Discussion}

Neonatal sepsis with its high mortality rate, still remains a diagnostic and treatment challenge for the neonatal health care providers. An early diagnosis of neonatal septicemia helps in instituting antibiotic therapy at the earliest time, thereby reducing the mortality rates and also avoids the unnecessary treatment of a non infected neonate. Mortality rate are high in the developing countries because of the lack of early diagnosis and identification of high risk cases ${ }^{[13]}$. Neonatal sepsis also increases the length of hospital stay and cost of treatment especially in developing countries with insufficient neonatal intensive care facilities and personnel. Blood culture which is gold standard for diagnosis of neonatal sepsis not 
only takes time, but it is also complicated, with a low yield ${ }^{[14]}$. For this reason, a number of biochemical markers have been tested for accurate diagnosis of sepsis in the shortest time ${ }^{[15]}$.

In this study, red cell distribution width was tested as an early inexpensive and easily available biomarker for diagnosis of neonatal sepsis. Mean age of cases was $26.56 \pm 19.00$ hours and that of controls was $26.07 \pm 12.31$ hours. Cosar $\mathrm{H}$ et al ${ }^{[15]}$ reported similar findings with mean age of cases being $1.98 \pm 0.9$ days and that of controls being $1.87 \pm 0.92$ Days. In the present study $67.27 \%$ of cases were male, similar male preponderance was found by cosarh et al ${ }^{[15]}$ and Betty chacko et $\mathrm{al}^{[16]}$. Medhat A Saleh et $\mathrm{al}^{[17]}$ however observed number of females to be more than male.

In present study the mean RDW level was significantly higher in neonatal sepsis cases $(21.31 \pm 3.08 \%)$ as compared controls $(16.23 \pm 1.16 \%)$. Jianping et $\mathrm{al}^{[18]}$, also found mean RDW level was significantly higher than sepsis group. This can be explained by the fact that inflammation causes an increase of neurohormone and endocrine hormone in the body including noradrenaline, angiotensin I and other angiotensin levels and renal ischemia. These neurotransmitters can stimulate red blood cell proliferation through increased secretion of erythropoietin (EPO) causing increase in RDW and inflammatory factors may affect marrow hematopoietic function and iron metabolism in the body to cause increase in RDW value ${ }^{[19]}$.

In this study, increased RDW was found in in term and near term infants with EONS. RDW is a low-priced arithmetical index and is part of a standard complete blood count. RDW is quickly obtained, and also does not require additional costs and can be provided easily. Comparative studies investigating the correlations between sepsis, septic shock and RDW have been more frequently performed with adult population. Chan Ho Kim et $\mathrm{al}^{(20)}$, in a study of 329 patients, found higher mortality rates in patients with higher RDW. In study by $\mathrm{Ku}$, Nam $\mathrm{Su}$; Kim et $\mathrm{al}^{[21]}$ including 566 adult patients, RDW was indicated as a potentially independent prognostic factor for 28 day-mortality in patients with sepsis and septic shock $^{(21)}$.

Christensen RD, Yaish $\mathrm{HM}$ et $\mathrm{al}^{[22]}$ investigated reference ranges of RDW for newborn, and detected lower and upper limits of normal at birth, for term and late-preterm infants as $15.5 \%$ and $20 \%$, respectively. However, in premature infants, upper limit of RDW was higher (23\%)43 In present study, RDW $(21.31 \pm 3.08 \%)$ measured within 4 days of the postnatal period was similar to the lower limit of normal reference range of term and late-term infants in the above-mentioned study.

Multivariate logistic regression analysis revealed RDW $(\mathrm{p}=0.005)$ and TLC $(\mathrm{P}=0.033)$ were independent predictors of EONS. Higher RDW strongly suggested of EONS (OR =50.39) and TLC $(\mathrm{OR}=1.204)$ was a weak indicator. Area under the ROC curve for RDW was found to be $0.988(0.973-1.000)$ indicating that RDW was a good predictor of EONS. The Critical cut off point was found to be 18.55 using Youden index which indicates that $\mathrm{RDW} \geq 18.55$ is diagnostic of EONS.

The sensitivity and specificity of RDW to detect EONS in cases included on the basis of clinical signs and culture positivity was $94.50 \%$ and $96.36 \%$ respectively. Abdullah ST et $\mathrm{al}^{(19)}$ in a study on 112 newborns, found that at cut off of RDW $14.3 \%$ had sensitivity and specificity of $85 \%$ and $100 \%$ respectively for diagnosis of sepsis.

Though the mechanism of increased RDW in Sepsis is not known, higher RDW levels demonstrate its association with inflammatory processes. It has been detected that markers of inflammation including RDW-associated interleukin-6 (IL-6), tumour necrosis factor-alfa $(\mathrm{TNF}-\alpha)$ and proinflammatory cytokines suppress maturation process of $\mathrm{RBC}$ and increase their half-lives with resultant rise in RDW levels ${ }^{[10,23]}$ 


\section{Conclusion}

RDW was observably higher in new-born with EONS. It is a hematological index estimated within the standard CBC profile and can be easily and rapidly estimated without additional cost. Further studies with preferably prospective design and wider clinical profile could help establish role of RDW alone or in combination other haematological score for early and rapid diagnosis of EONS.

\section{Conflict of interest: None}

\section{Bibliography}

1. Report of National Neonatal Perinatal Database (National Neonatology Forum) 2002-03

2. Ying F, and Jia-Lin Y. Umbilical blood biomarkers for predicting early onset neonatal sepsis. World J. Pediatr.2012; 8(2): $101-108$.

3. Anderson-Berry AL. and Ohning BL. Neonatal Sepsis. available from http://www.emidicine.com/ped/topic2630. html,2008

4. Tripathi S. and Malik G. Neonatal Sepsis: Past, Present And Future: A Review Article. Internet. J. Med. 2010; 5 (2): 4554

5. Gerdes JS. Diagnosis and management of bacterial infections in the neonate. Pediatr Clin N Am.2004; 51: 939-959.

6. Shah BA, Padbury JF. Neonatal sepsis: an old problem with new insights. Virulence.2014; 5: 170-178.

7. Töllner U. Early diagnosis of septicemia in newborn. Clinical studies and sepsis score. Eur J Pediatr .1982;138: 331-337.

8. Altunhan H, Annagür A, Örs R. Procalcitonin measurement at 24 hours of age may be helpful in the prompt diagnosis of early-onset neonatal sepsis. Int $\mathbf{J}$ Infect Dis.2011; 15: 854-858.
9. Arnon S, Litmanovitz I. Diagnostic tests in neonatal sepsis, Curr Opin Infect Dis.2008; 21: 223-227.

10. Jo YH, Kim K, Lee JH, Kang C, Kim T. Red cell distribution width is a prognostic factor in severe sepsis and septic shock. Am J Emerg Med.2013; 31: 545-548.

11. Sharma CM, Agrawal RP, Sharan H, Kumar B, Sharma D. "Neonatal Sepsis": Bacteria \& their Susceptibility Pattern towards Antibiotics in Neonatal Intensive Care Unit. J Clin Diagn Res.2013; 7: 2511-2513.

12. Aksoy HT, Eras Z, Canpolat E, Dilmen U. Does red cell distribution width predict mortality in newborns with early sepsis? Am J Emerg Med.2013; 31: 1150.

13. West B, Tabansi P. Prevalence of neonatal septicaemia in the University of Port Harcourt Teaching Hospital, Nigeria. Niger J Paed. 2014; 41(1):33-7.

14. Sharma M, Yadav A, Yadav S, Goel N, Chudhary U. Microbial profile of septicemia in children. Indian J. 2008; 5(4): $1-5$.

15. Cosar H, Yilmaz O, Temur M, Ozun OP, Bulut Y. Relationship between EarlyOnset Neonatal Sepsis and Red Blood Cell Distribution Width (RDW). J Hematol Thrombo Dis.2017,5: 266.

16. Chacko, Betty \& Sohi, Inderpreet. (2005). Early onset neonatal sepsis. Indian journal $\begin{array}{lll}\text { of } & \text { pediatrics. } & \text { 23-6. }\end{array}$ 10.1007/BF02760574.

17. Medhat A Saleh, Yasser T Kasem, Hesham H Amin. Evaluation of neonatal sepsis and assessment of its severity by Red Cell Distribution Width indicator. The Egyptian Journal of Community Medicine. 2017 july; 35(3):21-32

18. Jianping Chen1, Ling Jin1, Tong Yang. Clinical study of RDW and prognosis in sepsis new borns, Biomedical Research 2015; 25 (4): 576-579 
19. Abdullah ST, Moustafa AN, Mohsen Anwar A. Prognostic Validity of Red Cell Distribution Width in Neonatal Sepsis. Int J Pediatr 2018; 6(11): 8579-86. DOI: 10.22038/ijp.2018.33010.2917

20. Kim CH, Park JT, Kim EJ, Han JH, Han JS. An increase in red blood cell distribution width from baseline predicts mortality in patients with severe sepsis or septic shock. Crit Care.2013; 17: R282.

21. Jo YH, Kim K, Lee JH, Kang C, Kim T, et al. Red cell distribution width is a prognostic factor in severe sepsis and septic shock. Am J Emerg Med.2013; 31: 545-548.

22. Robert D. Christensen, Hassan M. Yaish, Erick Henry \& Sterling T. Bennett (2015) Red blood cell distribution width: reference intervals for neonates, The Journal of Maternal-Fetal \& Neonatal Medicine, 28:8, 883-888,

DOI: $10.3109 / 14767058.2014 .938044$

23. Lippi G, Targher G, Montagnana M, Salvagno GL, Zoppini G. Relation between red blood cell distribution width and inflammatory biomarkers in a large cohort of unselected outpatients. Arch Pathol Lab Med.2009; 133: 628-632. 